\title{
Diagnostic Interval: Experiences among Women with Breast Cancer in Malaysia
}

\author{
Wan Hasliza Wan Mamat ${ }^{1 * \mathbb{D}}$, Nikki Jarrett ${ }^{2} \mathbb{D}$, Susi Lund ${ }^{3} \mathbb{D}$ \\ ${ }^{1}$ Department of Professional Nursing Studies, Kulliyyah of Nursing, International Islamic University Malaysia, Selangor, \\ Malaysia; ${ }^{2}$ School of Health and Care Professions, University of Portsmouth, Portsmouth, United Kingdom; ${ }^{3}$ School of Health \\ Sciences, University of Southampton, Southampton, United Kingdom
}

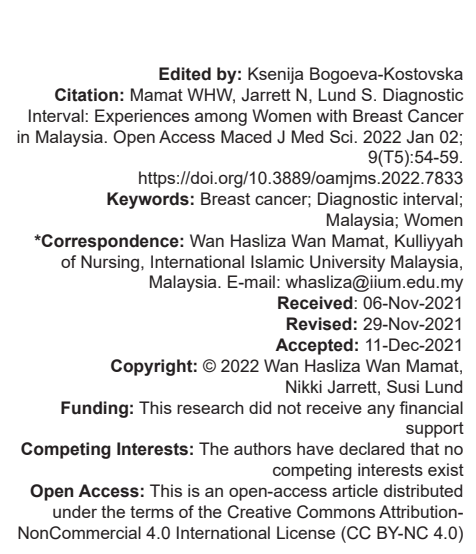

\section{Introduction}

Breast cancer is the most prevalent type of cancer in women worldwide, accounting for 2.3 million diagnosed cases [1]. Every $2 \mathrm{~min}$ [2] and every $10 \mathrm{~min}$ [3], respectively, a woman is diagnosed with breast cancer in the United States and the United Kingdom. This rate implies that a woman's lifetime risk of developing breast cancer at some point in her life is approximately 1 in 8 in the United Kingdom [4] and the United States [5]. Breast cancer affects $34.1 \%$ of all women living with cancer in Malaysia, according to the National Cancer Registry Report 2012-2016, and 1 in 27 women is likely to develop breast cancer during their lifetime [6]. According to the same report, $17.5 \%, 34.5 \%, 25.1 \%$, and $22.8 \%$ of breast cancer cases were diagnosed at stages I, II, III, and IV, respectively.

The diagnostic interval involves the period between "the first appointment with a healthcare professional and the formal diagnosis being made" [7]. During this interval, the patient has seen a doctor and has undergone several investigations before receiving a breast cancer diagnosis. Breast lumps, nipple abnormalities, breast pain, breast skin irregularities, and breast ulceration [8] are all characteristic symptoms of breast cancer. According to the Clinical Practice Guidelines for breast cancer management in Malaysia, patients presenting with breast symptoms should undergo a complete clinical examination, mammography, and/or ultrasound followed by biopsy, namely, fine needle and/or core biopsy [9]. This stage is critical because delaying cancer diagnosis or care increases the likelihood problem associated with treatment, higher of costs of care, and a lower chance of survival [10].

The barriers to timely cancer diagnosis and treatment have been primarily attributed to the characteristics of individual patients, and the healthcare system [11]. Therefore, gaining a better understanding of what occurs prior to cancer diagnosis will help provide a more accurate scenario of the current situation and aid in identifying levers for improving patients' prediagnostic pathways [12]. However, Malaysia persists to have inadequate research on the experiences of women with breast cancer, particularly during the diagnostic 
interval. This article summarizes findings from a larger study that included family members as participants. The primary research question for this article is: What are the experiences of Malaysian women during their breast cancer diagnostic interval?

\section{Methods}

\section{Design and sample}

A narrative approach was selected to understand Malaysian women's experiences during diagnostic interval for their breast cancer. Narrative is known as having the potential to give a voice to people that may reveal a deeper understanding of the tellers' own lives through the ability to bring out hidden and marginalised stories [13].

The participants were recruited from two hospitals located in urban area using purposive sampling based on the following criteria: (1) women; (2) diagnosed with primary breast cancer; (3) 18 years old and above; and (4) able to speak Malay or English.

\section{Ethical considerations}

Study participation was voluntary, and participants were assured of the right to withdraw at any point of the study with no consequences. Written consent was obtained from each participant prior to data collection. The interviews were recorded with participant's permission, and they were guaranteed confidentiality and anonymity of their data. Approval of ethics was obtained from the Faculty of Health Sciences, University of Southampton (Ethics no: 22983) and Research Ethics Committee, Malaysia Ministry of Health Research and Ethics Committee (NMRR-16-1319-31877).

\section{Procedures}

Data were collected through face-to-face, informal and unstructured interview using a piloted narrative script (Appendix). Most of the interviews took place in the participants' homes through their own choice. Only two interviews were conducted at the participants' workplace. Each interview lasted between 20 and $90 \mathrm{~min}$ (an average length of $32 \mathrm{~min}$ ). Eight interviews were conducted in Malay language and others were conducted in mixed English and Malay language. Since the researcher is fluent in both languages, there is no problem to understand the conversation with the participants. All the participants interviews were audiotaped and transcribed in verbatim. After completing the transcription process, the transcripts were read and re-read several times for the purpose of familiarisation and gaining a basic understanding of the participants' stories. Riessman [14] suggested that describing how the interpretations were produced enables the reader to determine the rigor in narrative research. In this study, the interpretations of the findings were based on the participants' interview transcripts, audio recordings, reflective diary and field notes. Moreover, frequent discussions with three experts in qualitative research improved the rigor in this study.

A narrative analysis described by Riessman was used to analyze the interviews [15]. Data analysis began with the structure of each narrative in order to examine the sequence of the events that had taken place. This process continues with analysis of the content of the narrative. Finally, the stage of interpretation, in which the narrative devices such as language, causality, temporality and contextual aspects were examined [15]. These included the use of imagery, metaphors, idioms and the repetition of words or phrases within their stories that provided clues for understanding how the participants perceived their experiences. After the individual analysis was completed, a search for commonalities across narratives was undertaken to look for patterns across the experiences of participants during diagnostic intervals. Finally, the selected quotes were translated to English for the purpose of publication.

\section{Results}

Throughout the period of data collection, 14 participants were interviewed. The background of the participants is summarized in Table 1.

Table 1: Demographic characteristics of the participants ( $n=14)$

\begin{tabular}{|c|c|}
\hline Participants & \\
\hline Age & 28-62 (mean: 46.1) \\
\hline \multicolumn{2}{|l|}{ Marital status } \\
\hline Single & 2 \\
\hline Married & 11 \\
\hline Widow & 1 \\
\hline \multicolumn{2}{|l|}{ Ethnicity } \\
\hline Malay & 9 \\
\hline Chinese & 3 \\
\hline Indian & 2 \\
\hline \multicolumn{2}{|l|}{ Occupation } \\
\hline Government & 6 \\
\hline Private & 2 \\
\hline Self-employment & 2 \\
\hline Not working & 4 \\
\hline \multicolumn{2}{|l|}{ Stage of breast cancer } \\
\hline Stage I & 2 \\
\hline Stage II & 4 \\
\hline Stage III & 7 \\
\hline Stage IV & 1 \\
\hline \multicolumn{2}{|l|}{ Treatment } \\
\hline Surgery & 7 \\
\hline Chemotherapy & 6 \\
\hline Radiotherapy & 1 \\
\hline \multicolumn{2}{|c|}{ Duration noticing symptom to first medical contact } \\
\hline$<1$ week & 8 \\
\hline 1 week to $<1$ month & 3 \\
\hline 1 month to $<3$ months & 1 \\
\hline 3 months to $<6$ months & 0 \\
\hline 6 months to $\leq 1$ year & 2 \\
\hline \multicolumn{2}{|c|}{ Duration first medical contact to diagnosis } \\
\hline 1 month & 6 \\
\hline 2 months & 7 \\
\hline 3 months & 1 \\
\hline
\end{tabular}


Four themes were identified regarding the diagnostic interval through narrative analysis: 1) Women who are suspected having breast cancer; 2) Women who experienced false reassurance; 3) Women who experienced delayed referral; and 4) Women who experienced unconfirmed investigation results. These quotations were purposively selected to illustrate the events in each theme.

\section{Theme 1: Women who are suspected of having breast cancer}

For the women in this study, doctors are critical because they are the first line of healthcare providers whom patients consult regarding their symptoms. Doctors' actions became a catalog of things that went wrong and served as the first indication of a serious health problem, which was diagnosed as breast cancer. This is evident in the following quotes:

After that, I went to a government clinic. The doctor referred me to the hospital. I went to hospital $X$, checked with Dr. A. Then, on the same day, he immediately asked me to have a mammogram and ultrasound. The next week, he asked me to do MRI. The following week, I did biopsis [biopsy]... From the start, I could see that the doctor seemed like he was rushing to do the test. I felt like like something was wrong. As usual practice, we tend to have late appointments, right, usually 2-3 weeks, but at that time, starting from the $1^{\text {st }}$ day I met with the doctor, that doctor seemed to want to do many things. So, I expected something serious, like cancer (Participant 6).

However, participant four reported that the doctor already suspected she probably had breast cancer during the investigation phase.

During the ultrasound, the doctor said, "This is not good, not fine." The doctor said "You may have cancer." The doctor said, "If this is cancer, you should not seek treatment at an inappropriate place" (Participant 4).

\section{reassurance \\ Theme 2: Women who experience false}

Some of the women in this study, who were initially aware of their breast symptoms, received a delayed diagnosis as a result of their first doctors making an incorrect initial assessment. Women's perceptions of their early signs were shaped by what their doctors had told them. They were positive and unconcerned about their circumstances. This is evident in the following quotes:

I said to that doctor, "I feel that I have a lump." She checked. She said, "It's nothing. No lump." But I thought that there was a lump present. It might be that it was small at the time. "Nothing", she said, "nothing"... When the doctor at the clinic $Y$ told that she did not feel anything, for me, it was fine. I felt relieved after the appointment (Participant 2).

The doctor said, "It's nothing. Lymph nodes only." S/he gave me medicine. S/he gave an antibiotic. I thought it was fine (Participant 10).

... My breast appears a bit firm, and GP said, "It was normal, nothing wrong." I accepted, "Okay, it was nothing" (Participant 12).

As a result, they began ignoring the symptoms. Several months later, they would notice more perceptible changes in their breasts. These women's stories indicated that they considered themselves victims as they expressed their negative emotions and reactions, implying a sense of dissatisfaction with the check-up they received from a healthcare professional in the first place. This is evident in the following quotes:

After that, when I went back to the clinic in July this year, I said, "Doctor, do you still remember me? I had my breast checked with you before. Look what's happened now?" At that time, I was very irritated (Participant 2).

Four to five months later, I realised that the thing had got bigger. I had already told the doctor. I was mad at that doctor. It was already quite big, $8 \mathrm{~cm}$ (Participant 10).

Three to four months later, the breast still firmed. I feel uneasy. It likes I heard something that whispers in my ear. So, I said "go and check." So, 1 day, I went to hospital $Y$ because it is located near to my house. I asked the doctor to do proper checking. The doctor checked and asked me to do ultrasound. Ultrasound showed a shadow. So, I have to do mammogram. Then confirm there is "something." (Participant 12)

\section{referral \\ Theme 3: Women who experience delayed}

In this study, one woman was referred late. Participant 8 sought medical consultation three times at the clinic for her pain, and it took more than a month for her to be referred to the hospital for further investigation.

So, I went to the ordinary clinic taking a medication. It seemed okay. Then it [pain] happened again. Three times it happened. So, after it happened for a third time, the doctor asked me to go to a hospital, referred me to the hospital ... during my first visit, the doctor gave Panadol. Second time, different painkiller (Participant 8).

\section{Theme 4: Women who experience} inconclusive investigations result

Occasionally, the conclusion of an investigation is delayed due to human error, technological error, or a 
characteristic of the cancer itself. Both events (biopsy and pathology results) may be regarded as errors in processes and procedures, but they already extend the diagnostic interval and result in delayed diagnosis. This is illustrated in the following quotes:

Two, three days after that, I went to the hospital again. Checked, checked, checked, checked. The doctor took, what is that called (p), took our meat (tissue) inside. Biopsy. Huh, biopsy. Two times she did it. At first, with the small needle. Cannot, unable to identify. The doctor did it again, on the following week. S/he did again (Participant 1).

I went back to that hospital, checked again. The doctor said it was a cyst. So, after they removed that (cyst), the doctor sent the specimen to the lab. They said it was CA (pronounced alphabetically), but CA mass mixed with cyst. So, they felt like it was unconfirmed, at that hospital A, where I had it (removal of cyst). Then I came to hospital Z. Hospital Z did the same thing, sending the specimen to the lab many times, because they were also unconfirmed (Participant 14).

\section{Discussion}

Diagnostic intervals have emphasized the physician's role in evaluating and investigating symptoms until a formal diagnosis is made. Even though some of the women sought medical consultation early on, this study found that it took between 1 and 3 months of diagnostic procedures to confirm the diagnosis of breast cancer. However, this interval was shorter compared to Pakistan [16] but was longer when compared to Morocco [17] and Thailand [18]. This situation may have occurred in Malaysia as a result of inadequate facilities and doctors, overcrowding, and lengthy waiting lists [19] for diagnostic tests and consultations, which may have delayed and impaired the early diagnosis of breast cancer in government hospitals.

Several of the women in this study reported receiving premature reassurance from the first medical doctor that they had consulted, despite the fact that they met with the doctor within 1-3 days of experiencing symptoms. They were initially diagnosed with benign conditions, such as swollen lymph nodes, normal breast firmness, or the absence of a lump. They felt as though their concerns were dismissed during their visit, during which no evidence of breast cancer was found; consequently, the women received false reassurance at the time. The HCP appraisal process can be subject to errors and biases during the diagnostic interval, which can result in misdiagnosis, dismissal of symptoms, or no diagnosis [8]. As a result of premature reassurance, the women in this study waited approximately 4 months to 1 year before returning to the doctor for a second session. This circumstance lengthened the interval and resulted in a delayed or missed diagnosis. This duration was nearly identical to that reported in a previous study, which indicated that false reassurance can persist for months, if not years, in relation to seeking help for subsequent cancer symptoms [20].

In this study, one woman sought medical consultation three times at the clinic and was referred to the hospital for further investigation more than a month later. Consultations are associated with a longer time period between presentation and referral for cancer treatment [21]. Cancer patients who received three or more pre-referral consultations typically had longer median intervals as well [22]. According to national audit data in the United Kingdom, the median time to referral is 34 days for patients who have three consultations, 47 days for patients who have four consultations, and 96 days for patients who have five or more consultations [22] Some researchers argued that prolonged diagnostic intervals reflect HCP's scientific knowledge and ability to deliver health care [21]. Therefore, the primary physician's inability to differentiate symptoms may explain why this situation occurred, even though no generalization can be drawn from one participant's account in this study.

Detection difficulties can be attributed to intrinsic characteristics of the tumor or surrounding tissue, technical problems, or human error [23]. Even when lesions are successfully detected, diagnostic delays can occur due to assessment or management recommendation errors [23]. Therefore, Artificial Intelligent technology is being designed to eliminate the unnecessary waiting time as well as reducing human and technical errors in diagnosing BC [24]. Gandhi et al. [25] found that $59 \%$ of diagnostic errors were caused by three or more process breakdowns, delaying diagnosis by an average of more than a year. Several of these injuries could have been prevented by ensuring an adequate medical history, physical examination, and follow-up plan.

While the participants exhibited a range of characteristics, including different stages of breast cancer, ethnicity, and age, this study focused on patients who sought medical treatment, excluding those who declined medical attention and those who ignored the symptoms. In addition, this study also focused on a specific setting, which may not be generalizable to other populations.

\section{Conclusion}

This study discovered that physicians' actions can have both positive and negative consequences. Some of the women were immediately referred to a tertiary hospital and subjected to multiple investigations, 
while others received premature reassurance from the first medical doctor they consulted. Their roles are regarded as one of the most significant determinants of breast cancer detection in the early stages. As a result, efforts must be made to minimize the risk of falsely assuring patients. This can be accomplished by informing patients about any uncertainties in the findings, explaining the symptom changes that require special attention, advising patients to seek immediate help-seeking behavior if necessary, and explaining the illness's potential progression over time [20]. Additionally, Gbenonsi et al. [26] stressed the importance of continuing medical education and training in breast cancer among healthcare professionals. Breast cancer knowledge and patient assessment appear to be critical for effective early detection in primary care.

Diagnostic investigations are frequently conducted sequentially, and the presence of limited resources, either in terms of staff or facilities, may account for the lengthy wait time and system delay observed in this study. Consequently, the government and policymakers must recognize and pursue initiatives to overcome systemic barriers to improve screening, diagnosis, and treatment accessibility. In limited-resource settings, simplicity in the diagnostic process is critical, and it is suggested that a combination of the numerous diagnostic tests available enables the establishment of a pathology diagnosis in a single visit [27].

While the participants provided limited information about the nurses' roles during this interval, it did identify areas where nurses could contribute by educating patients to monitor their symptoms and advising them that if the symptom worsen, they should immediately go to the hospital without waiting for their appointment day. Furthermore, nurses should educate patients about the dangers of seeking inappropriate treatment, such as from a "traditional" healer, as this may influence their subsequent decision. This study establishes a foundation for future research aimed at eliciting perspectives from healthcare providers who are directly involved in the diagnostic interval. Their data could then be used to improve the early detection or diagnosis of breast cancer in women.

\section{References}

1. World Health Organization. Breast Cancer. Geneva: World Health Organization; 2021. Available from: https://www.who.int/ news-room/fact-sheets/detail/breast-cancer [Last accessed on $2021 \mathrm{Jul} 10]$

2. National Breast Cancer Foundation. Breast Cancer Facts; 2021. Available from: https://www.nationalbreastcancer.org/breastcancer-facts [Last accessed on $2021 \mathrm{Jul} 10]$.

3. Breast Cancer Now. Facts and Statistics; 2021. Available from: https://www.breastcancernow.org/about-us/media/factsstatistics [Last accessed on $2021 \mathrm{Jul} 10]$.
4. National Cancer Institute. Breast Cancer Risk in American Women; 2019. Available from: http://www.cancer.gov/types/ breast/risk-fact-sheet [Last accessed on 2019 Jun 04]

5. Cancer Research UK. Breast Cancer Genes; 2019. Available from: http://www.cancerresearchuk.org/about-cancer/type/ breast-cancer/about/risks/breast-cancer-genes [Last accessed on 2019 Jan 10].

6. Azizah AB, Hashimah B, Nirmal K, Siti Zubaidah AR, Puteri NA, Nabihah $A$, et al. Malaysian National Cancer Registry Report 2012-2016. 2019. Malaysia: Ministry of Health.

7. Scott S, Walter F, Webster A, Sutton S, Emery J. The model of pathways to treatment: Conceptualization and integration with existing theory. Br J Health Psychol. 2013;18(1):45-65. https:// doi.org/10.1111/j.2044-8287.2012.02077.x

PMid:22536840

8. Koo MM, von Wagner C, Abel GA, McPhail S, Rubin GP, Lyratzopoulos G. Typical and atypical presenting symptoms of breast cancer and their associations with diagnostic intervals: Evidence from a national audit of cancer diagnosis. Cancer Epidemiol. 2017;48:140-6. https://doi.org/10.1016/j. canep.2017.04.010

PMid:28549339

9. Malaysia Ministry of Health. Management of Breast Cancer. Malaysia: Ministry of Health; 2010.

10. WHO. Promoting Cancer Early Diagnosis. Geneva: WHO 2021. Available from: https://www.who.int/activities/promotingcancer-early-diagnosis [Last accessed on 2021 Dec 01]

11. Getachew S, Tesfaw A, Kaba M, Wienke A, Taylor L, Kantelhardt EJ, et al. Perceived barriers to early diagnosis of breast cancer in South and Southwestern Ethiopia: A qualitative study. BMC Womens Health. 2020;20(1):38. https://doi. org/10.1186/s12905-020-00909-7

PMid:32103774

12. Provost $S$, Pineault $R$, Tousignant $P$, Roberge $D$, Tremblay $D$, Breton $\mathrm{M}$, et al. Does the primary care experience influence the cancer diagnostic process? Int J Family Med. 2015;2015:176812. https://doi.org/10.1155/2015/176812 PMid:26504599

13. Susinos T. 'Tell me in your own words': Disabling barriers and social exclusion in young persons. Disabil Soc. 2007;22:117-2.

14. Riessman CK. Narrative Analysis. London: SAGE; 1993.

15. Riessman CK. Divorce Talk: Women and Men Make Sense of Personal Relationship. USA: Rutgers University Press; 1990.

16. Majeed I, Ammanuallah R, Anwar AW, Rafique HM, Imran F. Diagnostic and treatment delays in breast cancer in association with multiple factors in Pakistan. East Mediterr Health J. 2021;27(1):23-32. https://doi.org/10.26719/emhj.20.051 PMid:33538316

17. Maghous A, Rais F, Ahid S, Benhmidou N, Bellahamou K, Loughlimi $\mathrm{H}$, et al. Factors influencing diagnosis delay of advanced breast cancer in Moroccan women. BMC Cancer. 2016;16:356. https://doi.org/10.1186/s12885-016-2394-y PMid:27268201

18. Poum A, Promthet S, Duffy SW, Parkin DM. Factors associated with delayed diagnosis of breast cancer in Northeast Thailand. J Epidemiol. 2014;24(2):102-8 https://doi.org/10.2188/jea. je20130090 PMid:24335087

19. Rasiah R, Yusof W, Nwagbara V. Performance of X-Ray and Fluoroscopy Machines in Public and Private Hospitals in Malaysia. Workshop, Healthcare Services in Malaysia: Are There Differences in the Practices, Performances and Charges Between Public and Private Hospitals; 2010.

20. Renzi C, Whitaker KL, Wardle J. Over-reassurance and undersupport after a 'false alarm': A systematic review of 
the impact on subsequent cancer symptom attribution and help seeking. BMJ Open. 2015;5(2):e007002. https://doi. org/10.1136/bmjopen-2014-007002

PMid:25652803

21. Lyratzopoulos $\mathrm{G}$, Wardle J, Rubin G. Rethinking diagnostic delay in cancer: How difficult is the diagnosis? BMJ. 2014;349:97400. https://doi.org/10.1136/bmj.g7400

PMid:25491791

22. Lyratzopoulos G, Abel G, McPhail S, Neal R, Rubin G. Measures of promptness of cancer diagnosis in primary care: Secondary analysis of national audit data on patients with $18 \mathrm{common}$ and rarer cancers. $\mathrm{Br} \mathrm{J}$ Cancer. 2013;108(3):686-90. https://doi. org/10.1038/bjc.2013.1

PMid:23392082

23. Giess CS, Frost EP, Birdwell RL. Difficulties and errors in diagnosis of breast neoplasms. Semin Ultrasound CT MR. 2012;33(4):288-99. https://doi.org/10.1053/j.sult.2012.01.007 PMid:22824119

24. Ortiz-Rodriquez JM, Guerrero-Mendez C, Martinez-Blanco MD, Castro-Tapia S, Moreno-Lucio M, Jaramillo-Martinez R, et al. Breast Cancer Detection by Means of Artificial Neural Networks; 2018. Available from: https://www.intechopen.com/ chapters/57365 [Last accessed on 2021 Dec 03].

25. Gandhi TK, Kachalia A, Thomas EJ, Puopolo AL, Yoon C, Brennan TA, et al. Missed and delayed diagnoses in the ambulatory setting: A study of closed malpractice claims. Ann Intern Med. 2006;145(7):488-96. https://doi. org/10.7326/0003-4819-145-7-200610030-00006 PMid:17015866

26. Gbenonsi G, Boucham M, Belrhiti Z, Nejjari C, Huybrechts I, Khalis M. Health system factors that influence diagnostic and treatment intervals in women with breast cancer in Sub-Saharan Africa: A systematic review. BMC Public Health. 2021;21:1325. https://doi.org/10.1186/s12889-021-11296-5

\section{PMid:34229634}

27. Shyyan R, Masood S, Badwe RA, Errico KM, Liberman L, Ozmen V, et al. Breast cancer in limited-resource countries: Diagnosis and pathology. Breast J. 2006;12 Suppl 1:S27-37. https://doi.org/10.1111/j.1075-122X.2006.00201.x PMid:16430396

\section{Appendix}

Hello. My name is. I am a PhD student at the University. Thank you for your support and your spending time with me today. I'm collecting life histories about decision-making related to breast cancer and I would be grateful if you would share your story with me. I will listen first and I will not interrupt, I may take a couple of notes if I need to ask you questions later for clarification. Please take the time that you need and as I said I will not interrupt you. So, may I ask you to share with me your story since you first thought that you may have a problem with your breast? The researcher continues to:

- Probe

- Rephrase/reframe

- Clarify

- Explore meaning in the conversation 